SECTION 21. Pedagogy. Psychology. Innovation in Education.

Sergey Alexandrovich Mishchik

Associate Professor, Candidate of Pedagogical Science,

Assistant professor Department of Physics,

State Maritime University Admiral Ushakov, Russia

sergei_mishik@mail.ru

\title{
SIMULATION TRAINING ACTIVITY METHODS OF MATHEMATICAL LOGIC
}

Abstract: Proposed simulation training activities methods of mathematical logic regarding the integrity of the educational process-system implementation guide based on mathematical modeling of psychological and pedagogical theory of activity, psychological and pedagogical System analysis and stepwise formation of mental actions with respect to integrity of the system life cycle.

Keywords: pedagogometrika, mathematical logic, educational action, activity, learning process, analysis, formation of mental actions

\section{УДК 372.851}

\section{МОДЕЛИРОВАНИЕ УЧЕБНОЙ ДЕЯТЕЛЬНОСТИ МЕТОДАМИ МАТЕМАТИЧЕСКОЙ ЛОГИКИ}

\begin{abstract}
Аннотация: Предложено моделирование учебной деятельности методами математической логики относительно целостно-системного учебного прочесса реализующего основы математического моделирования психолого-педагогической теории деятельности, психолого-педагогического системного анализа и теории поэтапного формирования умственных действий относительно целостно-системного ијикла жизнедеятельности.
\end{abstract}

Ключевые слова: педагогометрика, математическая логика, учебное действие, деятельность, учебный проиесс, анализ, формирование умственных действий

Моделирование учебной деятельности методами математической логики позволяет определить условия формирования современных методов педагогометрического констатирующего математического моделирования учебной деятельности, направленной на установление основных характеристик учебно-профессиональной личности в учебном процессе $[1,2]$.

Современные методы педагогометрического констатирующего математического моделирования учебной деятельности применяют различные теоретико-математические подходы, не считая методов математической статистики. Одним из таких направлений выбирается современная математическая логика, которая моделирует как содержательное, так деятельностное моделирование учебного процесса [2,9].

В качестве базисного математического образа выбираются логические функции. При моделировании содержания образования применяют нормальные формы логических функций. Дизъюнктивная (конъюнктивная) нормальная форма - это дизъюнкция (конъюнкция) конечного числа различных членов, каждый из которых представляет собой конъюнкцию (дизъюнкцию) отдельных переменных или их отрицаний, входящих в данный член не более одного раза[3].

Функция учебного действия приводится к нормальной форме и проводится по схеме: 1) с помощью законов де Моргана формула преобразуется к такому виду, чтобы 
знаки отрицания относились только к отдельным переменным; 2) на основе первого (второго) дистрибутивного закона формула сводится к дизъюнкции конъюнкций (конъюнкции дизъюнкций); 3) полученное выражение упрощается и соответствии с тождествами $x \cdot x=x$ и $x \cdot \bar{x}=0(x \vee x=x$ и $x \vee \bar{x}=1)$.

При формировании сложной учебной информации применяют алгебру Жегалкина, когда множество булевых функций строится на основе операций сложения по модулю 2 и конъюнкции[4].

Преимущество алгебры Жегалкина в математическом моделировании учебной деятельности состоит в арифметизации логики.

Применение контактных схем в моделировании учебного процесса устанавливает аналогию выполненных учебных действий с интерпретаций булевых функций в виде электрической схемы, состоящей из источника напряжения (батареи), лампочки и одного или двух ключей $x_{1}$ и $x_{2}$. Любую сложную булеву функцию учебного процесса можно представить некоторой переключательной схемой[5].

Задача анализа учебной деятельности состоит в построении соответствующей ей булевой функции. Для параллельно-последовательных схем эта задача решается на основе того, что параллельное соединение контактов соответствует дизъюнкции, а последовательное соединение - конъюнкции переменных, которыми эти контакты обозначены в схеме.

При построении контактной схемы по заданной булевой функции (задача синтеза) задаётся логической формулой и таблицей. Во всех случаях функции представляются через операции конъюнкции, дизъюнкции и отрицания. В процессе моделирования учебной деятельности применяются логические схемы[6].

Любая булева функция учебной деятельности представима в совершенной нормальной форме (дизъюнктивной или конъюнктивной). Это является условием перехода от табличного задания функции к её аналитическому выражению. Каноническая задача синтеза логических учебных действий в булевом базисе сводится к минимизации булевых функций, т.е. к представлению в дизъюнктивной нормальной форме, которая содержит наименьшее число переменных и их отрицания.

Формирование многомерного куба в моделировани учебного процесса позволяет каждой вершине n-мерного куба поставить в соответствии конституенту единицы.

Применение карт Карно в графическом моделировании учебной деятельности в методе графического отображения булевых функций, которые представляют собой специально организованные таблицы соответствия. Столбцы и строки таблицы соответствуют всевозможным наборам значений не более двух переменных[7].

При аналитическом моделировании учебного процесса применяют комплекс кубов схему многомерного логического пространства в сочетании со специально разработанной символикой.Комплекс кубов образует максимальное покрытие функции учебного процесса.

Постановка задачи минимизации и эффективности учебного процесса сводится к поиску минимальной дизъюнктивной формы, которой соответствует минимальное покрытие. Общее число букв, входящих в нормальную форму, выражается ценой покрытия $c=\sum_{s} q_{s}(n-s)$, где $q_{s}$ - число s-кубов, образующих покрытие данной функции от $\mathrm{n}$ переменных.

В процессе моделирования учебной деятельности применяют метод Квайна - Мак Класки, когда функция учебной деятельности задана в дизъюнктивной совершенной нормальной форме. Приведение к сокращённой форме происходит последовательным применением операции склеивания $a x_{i} \vee a x_{i}=a$, где $a$ - конъюнкции переменных отличных от $x_{i}$. 
В целом, применение методов математической логики задают современные методы педагогометрического констатирующего математического моделирования учебной деятельности, которая характеризуется в целостно-системном учебно-профессиональном цикле счётным количеством параметров, отражающих внутреннюю и внешнюю структуры совместной деятельности в системе преподаватель-студент заданной фундаментальности и широкопрофильности целостно-системной личности[8].

\section{References:}

1. Мищик С.А. Проектирование математических моделей физических объектов в процессе формирования целостно-системной самостоятельной учебной деятельности // Одиннадцатая международная конференция "Физика в системе современного образования" (ФССО - 11), 1 том - Волгоград.: Изд-во ВГПУ, 2011. - 318 с.

2. Мищик С.А. Организация лабораторного физического практикума на базе мобильных программ платформы андроид в процессе целостно-системной широкопрофильной подготовки // XII Международная учебно-методическая конференция "Современный физический практикум”, Москва, 25-27 сентября 2012 года. - Москва.: - Изд-во МГТУ им. Н.Э. Баумана - 325 с.

3. Мищик С.А. Целостно-системный цикл учебной жизнедеятельности - модель профессиональной деятельности широкопрофильного специалиста // Материалы Международной научной конференции «Деятельностная теория учения: современное состояние и перспективы», Москва. 6-8 февраля 2014 г. - М.: Издательство Московского университета, 2014. - 384 с.

4. Мищик С.А. Базисность. Фундаментальность. Широкопрофильность. Педагогометричность // Материалы Международной научной конференции «Moderni vymozenosti vedy - 2014». - Dil 16. Pedagogika.: Praha. Publishing House «Education and Science» S.r.o - 112 st.

5. Мищик С. А. Моделирование широкопрофильной целостно-системной деятельности // Материалы II Международной научной конференции «Приоритеты мировой науки: эксперимент и научная дискуссия»: 24-25 декабря 2013, г. С -Петербург North Charleston, SC, USA: CreateSpace, 2014. - $151 \mathrm{c}$.

6. Мищик С.А. Формирование целостно-системного цикла учебной жизнедеятельности широкопрофильного специалиста методами математического моделирования // Сборник материалов 3-й международной научно- практической конференции. 2 часть. Проблемы современной науки в 21 веке (г. Махачкала, 28 декабря 2013г.): Махачкала: ООО «Апробация», 2013 - 195 с.

7. Мищик С.А. Структурное формирование педагогометрических функций математического анализа целостно-системного учебного процесса// Материалы Международной научной конференции «Настоящи изследвания и развитие - 2014» 1725 януари, 2014. Том 14. Педагогически науки. - София, 2014: «Бял ГРАД-БГ» ООД $96 \mathrm{c}$.

8. Мищик С.А. Педагогометрика и математическое моделирование учебной деятельности. ISJ Theoretical \& Applied Science, -№ 6 (14), 2014 (ISPC Modern mathematics in science, 30.06.2014, Caracas, Venezuela), pp.54-56

9. Токмазов Г.В. Математическое моделирование в учебно-профессиональной деятельности. ISJ Theoretical \& Applied Science, -№ 6 (14), 2014 (ISPC Modern mathematics in science, 30.06.2014, Caracas, Venezuela), pp.44-46 